\title{
ANALISIS EFISIENSI DAN NILAI TAMBAH GULALI GULA MERAH DI DESA NYABAKAN BARAT KECAMATAN BATANG-BATANG
}

\author{
Mohammad Walid Wahdiy ${ }^{1 *}$, Purwati Ratna Wahyuni ${ }^{2}$, Ika Fatmawati Pramasari ${ }^{3}$ \\ ${ }^{1,2,3}$ Prodi Agbribisnis Fakultas Pertanian Universitas Wiraraja \\ Jl. Raya Sumenep-Pamekasan km 05 Patean, Kabupaten Sumenep, Jatim 69451; \\ 1․ Mohammadwalid962@gmail.com,
}

\begin{abstract}
ABSTRAK
Mengolah gula merah siwalan menjadi gula merah memberikan nilai tambah yang dapat meningkatkan pendapatan dan kesejahteraan para produsen gula merah, dan juga dapat membuat konsumen tertarik untuk mencoba dan membelinya. Analisis data menggunakan metode kuantitatif. Analisis dilakukan atas nilai efisiensi dan nilai tambahi. Pengolahan tebu coklat di Desa Nyabakan Barat, Kabupaten Batang-Batang efisien, ini dapat ditunjukkan dengan rasio R/C 1,46 (lebih besar dari satu). Ini berarti bahwa setiap modal 100 rupiah mendapat 146 rupiah. 2. Pengolahan tebu merah di Desa Nyabakan Barat, Kabupaten BatangBatang mampu memberikan nilai tambah positif sebesar 54,35\%.
\end{abstract}

Kata kunci: Efisiensi, gulali, nilai tambah.

\begin{abstract}
Processing siwalan brown sugar into brown sugar candy gives added value that can increase the income and welfare of the brown sugar producers, and can also make consumers interested in trying and buying it. The data analysis method used is quantitative analysis, namely value added analysis and efficiency analysis. The processing of brown sugar cane in Nyabakan Barat Village, Batang-Batang District is efficient, this can be indicated by the R I $C$ ratio of 1.46 (greater than one). This means that every 100 rupiah of capital gets 146 rupiah. 2. The processing of brown sugar cane in Nyabakan Barat Village, Batang-Batang District is able to provide positive added value of $54.35 \%$.
\end{abstract}

Keywords: Efficiency, gulali, value Added,

\section{PENDAHULUAN}

Sub sektor perkebunan merupakan bagian dari sektor pertanian yang cukup penting untuk kemajuan dan pembangunan Indonesia. Dalam sektor perkebunan yang banyak dilestarikan dan dibudidayakan oleh industri adalah gula merah yang bahan bakunya berasal dari pohon siwalan. Siwalan termasuk hasil perkebunan yang menghasilkan produk berupa gula. Setiap 100 cc nira siwalan umumnya mampu menghasilkan kurang lebih 15 g gula siwalan, nira siwalan didapatkan dari hasil sadapan unga nira siwala (Kirana, Hastuti, \& Suarsini, 2016)(Mubin \& Zubaidah, 2016). Gula merah siwalan mempunyai rasa yang berbeda dengan gula merah lainnya yaitu berasa lebih manis dan tajam, sehingga gula merah dari siwalan banyak digunakan dalam pengolahan pangan pada skala industri. Banyaknya peminat untuk menggunakan gula merah siwalan 
mengakibatkan harga gula merah siwalan lebih tinggi dibandingkan harga gula merah dari nira kelapa.

Gulali gula merah saat ini memang kurang diminati dipasar karena gulali gula merah merupakan makanan tradisional sebagai bentuk difersifikasi pengolahan pangan berbasis gula merah siwalan dimana di lokasi penelitian cukup banyak masyarakat yang memiliki kebun siwalan yang diolah menjadi gula siwalan. Hal inilah yang menjadi motivasi bagi pengolah gulalu untuk terus memproduksi gulali gula merah meskipun makanan khas tradisional ini kurang banyak peminatnya.

Pengolahan pangan berbasis bahan lokal juga peru dipertahakan sebagai upaya untuk meningkatkan pendapatan penduduk lokal (Saugi \& Sumarno, 2015), dalam hal ini dengan cara mempertahankan keberlanjutan usaha gulali gula merah. Untuk itu maka penting dilakukan analisis terhadap nilai tambah dan kelayakan melalui analisis efisiensi.

\section{METODE PENELITIAN}

\section{Metode Pengambilan Sampel}

Penelitian yang peneliti lakukan menggunakan metode sampel jenuh, karena jumlah pembuat gulali di Desa Nyabakan Barat Kecamatan Batang-Batang hanya ada 8 populasi pembuat gulali. Bila jumlah populasi kecil, kurang dari 30 orang maka digunakan sampling jenuh, sampling jenuh adalah teknik penentuan sampel apabila semua anggota populasi digunakan sebagai sampel (Bulan, 2016).

\section{Metode Analisis Data}

Metode analisis data yang digunakan adalah analisis kuantitatif. Analisis dilakukan untuk mengetahui nilai tambah produksi gulali gula merah serta kelayakan usaha melalui analisis efisiensi ( $\mathrm{R} / \mathrm{C}$ rasio). Dalam analisis kuantitatif ini dibuat batasan. Harga input dan output yang digunakan dalam penelitian ini mengikuti harga yang berlaku pada saat penelitian ini berlangsung. Untuk menganalisis pendapatan atau keuntungan digunakan rumus sebagai berikut:

Biaya :

$$
\begin{aligned}
& \mathbf{T C}=\mathbf{V C}+\mathbf{F C} \\
& \mathrm{TC}=\text { Total Cost } \\
& \text { VC }=\text { Varibel Cost (BiayaVariabel) } \\
& \text { FC }=\text { Fixed Cost (Biaya Tetap) }
\end{aligned}
$$

\section{Penerimaan:}

$\mathbf{T R}=\mathbf{P} \times \mathbf{Q}$

$\mathrm{TR}=$ Total Revenue

$\mathrm{P}=$ Price (harga)

$\mathrm{Q}=$ Quantum (JumlahProduksi)

\section{Pendapatan :}

$$
\begin{aligned}
& \pi=\text { TR }- \text { TC } \\
& \pi=\text { Pendapatan } \\
& \text { TR }=\text { Total Penerimaan } \\
& \text { TC }=\text { Total Biaya }
\end{aligned}
$$

\section{Efisiensi}

Suatu usaha dikatakan efisien apabila pendapatan/keuntungan yang diterima tinggi sementara biaya pengeluaran atau yang dikeluarkan rendah. Untuk mengukur efisiensi sebuah usaha dilakukan dengan cara memperbandingkan keuntungan atau penerimaan dan total biaya denga nrumus sebagai berikut:

$$
R / C \text { ratio }=\frac{\text { penerimaan }}{\text { totalbiaya }}
$$

Dengan pengertian bahwa nilai $\mathrm{R} / \mathrm{C}$ ratio menunjukkan perbandingan pendapatan dengan semua biaya yang dikeluarkan dengan kriteria sebagaiberikut :

$\mathrm{R} / \mathrm{C}>1$ berarti usaha home industri gulali tersebutefisien/menguntungkan.

$\mathrm{R} / \mathrm{C}<1$ berarti usahaagroindustri gulali tersebut tidak efisien. 
$\mathrm{R} / \mathrm{C}=1$ berarti usaha agroindustrigulali tersebut tidak untung dan tidak rugi. (Rusdiana \& Mushollaeni, 2009).

\section{HASIL DAN PEMBAHASAN}

\section{Analisis Nilai Tambah}

\section{Biaya Tetap}

Biaya tetap merupakan biaya yang lama atau tidak sekali pemakaian (Pertiwi, Hasnawati, \& Herawaty, 2018). Untuk menghitung nilai tambah pada produksi gulali gula merah diperlukan data biaya penyusutan. Tabel 1 merupakan rincian biaya penyusutan peralatan pada pembuatan gulali gula merah.

dikeluarkan dalam jangka waktu yang cukup

Tabel 1. Biaya Penyusutan Peralatan Pembuatan Gulali Gula Merah

\begin{tabular}{llcccc} 
No & Uraian & $\begin{array}{c}\text { Jumlah } \\
\text { (Unit) }\end{array}$ & $\begin{array}{c}\text { Harga Beli Alat } \\
\text { (Rp) }\end{array}$ & $\begin{array}{c}\text { Umur } \\
\text { Ekonomis } \\
\text { (Bulan) }\end{array}$ & $\begin{array}{c}\text { Nilai } \\
\text { Penyusutan/Bulan } \\
\text { (Rp) }\end{array}$ \\
\hline 1 & & & 218.750 & 96 Bulan & 2.282 \\
2 & Wompor & 1 & 24.687 & 36 Bulan & 686 \\
3 & Cetok & 1 & 11.812 & 24 Bulan & 492 \\
4 & Alat Pengaduk & 1 & 10.250 & 6 Bulan & 1.610 \\
5 & Alat Pemarut & 2 & 12.875 & 24 Bulan & 778 \\
6 & Tampah & 2 & 32.000 & 60 Bulam & 1.133 \\
7 & Baskom & 2 & 31.375 & 36 Bulan & 1.514 \\
& & Total Penyusutan & & $\mathbf{8 . 4 9 6}$
\end{tabular}

Dari tabel 1 diatas dapat dilihat bahwa dari semua biaya penyusutan didapat nilai rata-rata sebesar 8.496 hasil tersebut merupakan hasil total biaya penyusutan peralatan produksi keseluruhan gulali gula merah perbulan.

Biaya tetap dalam pembuatan gedung dan biaya penyusutan peralatan. Biaya tetap sebagaimana disajikan pada Tabel 2. Biaya sewa gedung merupakan biaya yang harus dikeluarkan untuk menyewa gedung selama keperluan proses produksi gulali gula merah dalam satu bulan. gulali gula merah terdiri dari biaya sewa Tabel 2. Biaya Tetap Pembuatan Gulali Gula Merah

\begin{tabular}{ccc}
\hline No & Jenis Biaya & Jumlah/Bulan (Rp) \\
\hline 1 & Biaya Penyusutan Alat & $\mathbf{8 . 4 9 6}$ \\
2 & Biaya Sewa Gedung & $\mathbf{4 6 . 3 5 4}$ \\
& Total Biaya & $\mathbf{5 4 . 8 5 0}$ \\
\hline
\end{tabular}

Dari tabel 2 diatas dapat dilihat bahwa total biaya tetap yang harus dikeluarkan oleh produsen pembuat gulali gula merah/bulan sebesar 54.850.

\section{Biaya Tidak Tetap}

Biaya tidak tetap merupakan biaya dengan jumlah totalnya akan mengalami perubahan sebanding dengan perubahan Tabel 3. Biaya Tidak Tetap Pembuatan Gulali Gula Merah

\begin{tabular}{lll}
\hline No & Jenis Biaya & Jumlah/Bulan (Rp) \\
\hline
\end{tabular}
volume kegiatan (Affandi, 2013). Dalam
proses produksi gulali gula merah yang termasuk biaya tidak tetap adalah baiya bahan baku, biaya tenaga kerja, sumbangan input lain. Adapun biaya tidak tetap dalam proses produksi gulali gula merah dapat dilihat pada tabel 3. 


\begin{tabular}{llc}
\hline 1 & Biaya Bahan Baku & 92.000 \\
2 & Biaya Tenaga Kerja & 28.906 \\
3 & Sumbangan Input Lain & 20.999 \\
& Total Biaya & $\mathbf{1 4 1 . 9 0 6}$ \\
\hline
\end{tabular}

Tabel 3 memperlihatkan bahwa hasil biaya tidak tetap meliputi bahan baku berupa gula merah dan kelapa adalah sebesar 92.000 dan biaya tenaga kerja sebesar 28.906 kemudian biaya sumbangan input lain yang meliputi plastik

\section{Biaya Total Pembuatan Gulali Gula Merah}

Biaya total dalam proses produksi gulali merah didapatkan dari total biaya Tabel 4. Biaya Total Pembuatan Gulali Gula Merah

\begin{tabular}{|c|l|c|}
\hline No & \multicolumn{1}{|c|}{ Jenis Biaya } & Jumlah/Bulan (Rp) \\
\hline 1 & Biaya Tetap & $\mathbf{5 4 . 8 5 0}$ \\
\hline 2 & Biaya Tidak Tetap & $\mathbf{1 4 1 . 9 0 6}$ \\
\hline \multicolumn{2}{|c|}{ Total Biaya } & $\mathbf{1 9 6 . 7 5 6}$ \\
\hline
\end{tabular}

Dari tabel diatas dapat terlihat bahwa total keseluruhan biaya yang dikeluarkan oleh produsen gulali gula merah setiap bulannya. Biaya tetap sebesar

\section{Analisis Efisiensi Usaha}

Analisis yang dilakukan untuk mengetahui tingkat efisiensi usaha yaitu menggunakan analisis rasio R/C. Analisis efisiensi termasuk dalam analisis kelayakan dalam investasi usaha (Ismawati \& Putri, 2018), dalam hal ini dilakukan untuk mengetahui pengolahan gulali gula merah ini secara finansial. Layak tidaknya atau efisien tidaknya suatu usaha tergantung pada tingkat $\mathrm{R} / \mathrm{C}$ rationya.

Tabel 5. Perhitungan R/C ratio Agroindustri Gulali Gula Merah

\begin{tabular}{|c|c|c|}
\hline Penerimaan/Pendapatan & Total Biaya & R/C ratio \\
\hline 287.500 & 196.756 & 1,46 \\
\hline
\end{tabular}

54.850 kemudian ditambah dengan biaya tidak tetap sebesar 141.905 dengan total biaya sebesar 196.756.

Semakin tinggi tingkat nilai ratio dari $\mathrm{R} / \mathrm{C}$ maka semakin efisien usaha usaha tersebut dan semakin layak untuk dikembangkan lebih lanjut. Perhitungan $\mathrm{R} / \mathrm{C}$ ratio didapat dari membandingkan tingkat pengeluaran dengan penerimaan (Asnidar \& Asrida, 2017). Pada agroindustri gulali gula merah ini di dapatkan hasil perhitungan rasio $\mathrm{R} / \mathrm{C}$ sebagaimana terdapat pada tabel 5 . dan gas sebesar 20.999 dan total keseluruhan biaya tidak tetap sebesar 141.905. biaya tersebut adalah biaya yang harus dikeluarkan dalam satu bulan proses produksi.

biaya tetap dan total biaya tidak tetap yang keduanya dijumlahkan. Besarnya biaya total dalam proses produksi gulali gula merah sebagaimana disajikan pada tabel 4 . 
Semua total penerimaan yang didapat yaitu sebesar 287.500 akan dibagi dengan total semua biaya yang dikeluarkan selama proses produksi yaitu sebesar 196.756 dan menghasilkan rasio $\mathrm{R} / \mathrm{C}$ dengan nilai 1,46 yang artinya usaha pengolahan gulali gula merah menguntungkan atau efisien berdasarkan analisis rasio R/C. Artinya setiap pengeluaran 100 rupiah akan mendapatkan 146 rupiah.

Tabel 6. Analisis Nilai Tambah Gulali Gula Merah di Desa Nyabakan Barat Kecamatan Batang-Batang.

\begin{tabular}{clc}
\hline No & \multicolumn{1}{c}{ Output, Input, Harga } & Persamaan \\
\hline 1. & Bahan baku (Kg/prod) & 8,62 \\
2. & Hasil produksi (Kg/prod) & 5,75 \\
3. & Jumlah tenaga keja (HOK/prod) & 2 \\
4. & Faktor Konversi & 0,66 \\
5. & Koefisiensi tenaga kerja & 0,23 \\
6. & Harga produk rata-rata (Rp/kg) & 50.000 \\
7. & Upah rata-rata (Rp/kg) & 28.906 \\
\hline & Penerimaan/Pendapatan & \\
\hline 8. & Harga bahan baku (Rp/kg) & 16.000 \\
9. & Sumbangan inpu laint (Rp/kg) & 2.436 \\
10. & Nilai produk (Rp/kg) & 33.000 \\
11. & a. Nilai tambah (Rp) & 14.564 \\
& b. Rasio nilai tambah (\%) & $44,13 \%$ \\
12. & a. Imbalan tenaga kerja (Rp/kg) & 6.648 \\
& b. Bagian tenaga kerja (\%) & $45,64 \%$ \\
13. & a. Keuntungan (Rp/kg) & 7.916 \\
& b. Tingkat keuntungan pengolah (\%) & $54,35 \%$ \\
\hline
\end{tabular}

Berdasarkan tabel 6, analisis nilai tambah diatas dapat diketahui bahwa faktor konversinya 0,66 sementara koefisiensi tenaga kerja adalah 0,23.

Nilai produk yaitu 33.000 dan nilai tambah yang dihasilkan sebesar 14.564. Imbalan tenaga kerja sebesar 6.648 dengan nilai bagian tenaga kerja adalah 45,64\% dan keuntungan yang didapat sebesar 7.916 .

\section{KESIMPULAN}

\begin{abstract}
Analisis Nilai Tambah
Tujuan analisis ini adalah untuk melihat seberapa besar nilai tambah yang terdapat pada usaha pembuatan gulali gula merah di Desa Nyabakan Barat Kecamatan Batang-Batang. Tabel perhitungan analisis nilai tambah sebagaimana disajikan pada tabel 6 .
\end{abstract}

1. Pengolahan gulali gula merah di Desa Nyabakan Barat Kecamatan Batang-Batang efisien, hal ini dapat ditunjukkan dengan nilai $\mathrm{R} / \mathrm{C}$ ratio sebesar 1,46 (lebih besar dari satu). Artinya setiap modal 100 rupiah mendapatkan sebesar 146 rupiah.

2. Pengolahan gulali gula merah di Desa Nyabakan Barat Kecamatan Batang-Batang mampu memberikan nilai tambah yang positif sebesar $54,35 \%$. 


\section{SARAN}

1) Efisiensi biaya produksi yang telah mampu dicapai agroindustri gulali gula merah hendaknya tetap dipertahankan agar keuntungan yang sudah diproleh dapat bertahan bahkan meningkat.

2) Usaha agroindustri gulali gula merah hendaknya memiliki ijin sehingga memberikan kepercayaan terhadap konsumen.

3) Lebih diperlakukannya perhatian secara khusus kepada agroindustri dari pemerintah berupa penataan serta memfasilitasi segala hal yang berhubungan dengan kegiatan agroindustri berkelanjutan dan pengembangan usaha agroindustri gulali gula merah di Desa Nyabakan Barat Kecamatan Batang-Batang.

\section{DAFTAR PUSTAKA}

Affandi, A. M. (2013). Laporan hasil penelitian analisis kelayakan usaha pembenihan ikan lele dumbo (.

Asnidar, \& Asrida. (2017). ANALISIS KELAYAKAN USAHA HOME INDUSTRY KERUPUK OPAK DI DESA PALOH MEUNASAH DAYAH KECAMATAN MUARA SATU KABUPATEN ACEH UTARAle. S. Pertanian, 1(1), 39-47.

Bulan, T. P. L. (2016). Pengaruh Labelisasi Halal terhadap Keputusan Pembelian Sosis di Kuala Simpang Kabupaten Aceh Tamiang. Jurnal Manajemen Dan Keuangan, 5(1), 430-439.
Ismawati, I., \& Putri, R. D. (2018). Uji

Kesukaan dan Kelayakan Usaha Produk Nugget Ikan Lele. Pertanian Cemara, 15(2), 1-5.

Kirana, C., Hastuti, U. S., \& Suarsini, E. (2016). Kajian Kualitas Nata de Nira Siwalan (Borassus Flabelliver L) dengan Variasi Macam Gula dalam Beberapa Konsentrasi sebagai Materi Handout Biologi Kelas XII MAN Pamekasan. Proceeding Biology Education Conference (ISSN : 2528 5742), 13(1), 178-186. Retrieved from https://jurnal.uns.ac.id/prosbi/article/v iewFile/5688/5056

Mubin, M. F., \& Zubaidah, E. (2016). ( PENGARUH PENGENCERAN NIRA SIWALAN DAN METODE INKUBASI ) Study of Making Palm ( Borassus flabellifer L .) Sap Kefir ( Palm Dilution and Incubation Methods Effect ), 4(1), 291-301.

Pertiwi, A. R., Hasnawati, \& Herawaty, V. (2018). LABA DENGAN UKURAN PERUSAHAAN SEBAGAI VARIABEL MODERASI ( STUDI EMPIRIS MANUFAKTUR YANG. Jurnal MAgister Akuntansi Trisakti, 5(1), 39-62.

Rusdiana, E., \& Mushollaeni, W. (2009). Pengolahan Nugget Komposit. Nuana Sains, 9(2), 191-195.

Saugi, W., \& Sumarno, S. (2015). Pemberdayaan perempuan melalui pelatihan pengolahan bahan pangan lokal. Jurnal Pendidikan Dan Pemberdayaan Masyarakat, 2(2), 226. https://doi.org/10.21831/jppm.v2i2.63 61 